LINGUA, Vol. 14, No. 1, Maret 2017

p ISSN: 1979 9411; e ISSN: 2442 238X

Http://lingua.pusatbahasa.or.id; Email: presslingua@gmail.com

Center of Language and Culture Studies, Surakarta, Indonesia

Haeruddin. 2017. Sistem Sapaan Kekerabatan Suku Sasak: Kajian Linguistik Kebudayaan.

Lingua, (2017), 14(1): 39 54.

\title{
SISTEM SAPAAN KEKERABATAN SUKU SASAK: KAJIAN LINGUISTIK KEBUDAYAAN
}

\author{
Haeruddin \\ Pascasarjana Pendidikan Bahasa Indonesia \\ Universitas Mataram \\ Jl. Pemuda No. 35 Mataram 83125, Nusa Tenggara Barat \\ Email: haeruddinpns1978@ gmail.com
}

\section{Diterima tanggal: 10 Desember 2016 \\ Diterima untuk diterbitkan tanggal: 1 Januari 2017}

\begin{abstract}
This study investigates kinship greeting in Sasaknese. The study used ethnolinguistic approach that described aspects of relation between language and culture to maintain cultural practices and social structure of a society. The study revealed: (1) the Sasak kinship greetings had relation to the kinship structure, having hierarchical boundaries of four generations above one's family group chart and three generations below one's family group chart, and are related to users' age; (2) the custom greetings have social and cultural functions; (3) the existing condition of the use of the kinship greetings is undergoing a shifting in some areas on Lombok Island as a result of modernization. The shifting is merely occurred on the greetingforms; whereas others, which are related to the kinship structure and the users' age, remain as the characteristic of Sasak tribe; (4) by constantly using the kinship greetings, Sasak people, have participated in preserving the cultural riches; that is the local language. This effort constitutes one of the strategies in preventing language extinction as the cultural heritage of the nation.
\end{abstract}

Key-words: Sasaknese, kinship, greeting, cultural heritage.

Keanekaan budaya merupakan ciri utama masyarakat Indonesia. Salah satu petunjuk adanya keanekaan tersebut adalah bahasa. Secara umum bahasa-bahasa di Indonesia digolongkan atas dua bagian. Pertama, bahasa Indonesia yang berkedudukan sebagai bahasa kebangsaan (nasional) dan kenegaraan. Kedua, bahasa-bahasa Nusantara-yang beratus-ratus jumlahnya yang berkedudukan sebagai bahasa daerah. Berdasarkan kedudukan itu, bahasa pun memiliki keteraturan pemakaian yang berbedabeda. Namun, kenyataannya, budaya bahasa itu tetap hidup dan berkembang di dalam masyarakat Indonesia.

Salah satu bahasa daerah yang dimaksud adalah bahasa Sasak. Selain itu, di pulau Lombok dibagi menjadi empat kabupaten dan satu kota, yaitu Lombok Timur, Lombok Tengah, Lombok Barat, Lombok Utara dan Kota Mataram. Disamping bahasa 
LINGUA, Vol. 14, No. 1, Maret 2017

p ISSN: 1979 9411; e ISSN: 2442 238X

Http://lingua.pusatbahasa.or.id; Email: presslingua@gmail.com

Center of Language and Culture Studies, Surakarta, Indonesia

Haeruddin. 2017. Sistem Sapaan Kekerabatan Suku Sasak: Kajian Linguistik Kebudayaan.

Lingua, (2017), 14(1): 39 54.

Indonesia sebagai bahasa nasional, penduduk pulau Lombok (terutama suku Sasak), menggunakan bahasa Sasak (bahasa asli) sebagai bahasa utama dalam percakapan sehari-hari. Di seluruh Lombok sendiri bahasa Sasak dapat dijumpai dalam lima macam dialek yang berbeda yakni dialek Lombok Lombok Utara, Lombok Tengah, Lombok Timur, Lombok Barat dan kota Mataram. Selain itu dengan banyaknya penduduk suku Bali yang berdiam di Lombok (sebagian besar berasal dari eks Kerajaan Karangasem), di beberapa tempat terutama di Lombok Barat dan Kota Mataram dapat dijumpai perkampungan yang menggunakan bahasa Bali sebagai bahasa percakapan sehari-hari.

Pulau Lombok luasnya $5.435 \mathrm{~km}^{2}$ adalah sebuah pulau dikepulauan Sunda Kecil atau Nusa Tenggara yang terpisahkan oleh Selat Lombok dari Bali di sebelah barat dan Selat Alas di sebelah timur dari Sumbawa. Sementara itu bahasa Sasak hidup dan berkembang didukung oleh masyarakat penuturnya. Dukungan tersebut sudah tentu menandai fungsi, kedudukan, dan peran bahasa Sasak bagi penuturnya sekaligus mempertahankan daya hidup dan keberadaannya. Intraksi yang terjadi antara penutur itu ditentukan oleh aturan social tertentu yang dimiliki masyarakat.

Bilan berintraksi dengan individu lain, seorang individu harus dapat meyesuaikan perilakunya (termasuk perilaku bahasanya) terhadap lingkungannya. Perilaku berbahasa ditentukan oleh bermacam-macam variabel, antara lain identitas lawan bicara, situasi, dan tempat terjadinya pembicaraan (setting), dan jenis kelamin lawan bicara. Unsur-unsur tersebut dinamakan variabel nonlingustik (Labob via Purnawa, 2003:2). Menurut Fisman dalam purnam, variabel tersebut berhubungan dengan siapa yang berbicara, dengan bahasa apa, kepada siapa, dan kapan.

Sesuai dengan kedudukan dan fungsi bahasa Sasak yang khas, penelitian bahasa Sasak perlu dan penting dilakukan dari berbagai aspek kebahasaan bagi bahasa yang memiliki kedudukan dan prestise yang dipandang tinggi (Margono 1986). Beberapa peneliti telah dilakukan terhadap bahasa Sasak, misalnya Kajian Makna, Nilai dan Simbol-Simbol Kebudyaan Masyarakat Suku Sasak oleh Hasbi Sidqi dalam makalahnya, Kajian Etnolinguistik terhadap Peribahasa Sasak, representasi kearifan logat lokal dalam bahasa sasak.

Beberapa aspek kebahasaan bahasa Sasak sudah diteliti. Namun, dipandang perlu adanya usaha penelitian lanjut untuk mencari temuan baru yang belum diteliti sama sekali. Dalam usaha kesinambungan dan kelengkapan inventarisasi dan pendokumentasian bahasa Sasak, penelitian sistem sapaan bahasa Sasak merupakan salah satu usaha kearah itu.

Penelitian sistem sapaan kekerabatan bahasa Sasak belum pernah dilakukan. Namun, beberapa penelitian yang sudah dilakukan dapat menunjang penelitian ini, yang tentu saja bukan hanya sekadar penginventarisasian, melainkan juga dapat memperlihatkan kekhasan sistem sapaan bahasa Sasak. Selain itu penelitian ini bermanfaat bagi masyarakat penuturnya karena sebagian sapaan yang masih berlaku sekarang mungkin akan berubah atau akan dilupakan orang sehingga pada suatu waktu nanti tidak dipakai lagi oleh penuturnya karena pengaruh mobilisasi sosial budaya yang cukup deras. 
LINGUA, Vol. 14, No. 1, Maret 2017

p ISSN: 1979 9411; e ISSN: 2442 238X

Http://lingua.pusatbahasa.or.id; Email: presslingua@gmail.com

Center of Language and Culture Studies, Surakarta, Indonesia

Haeruddin. 2017. Sistem Sapaan Kekerabatan Suku Sasak: Kajian Linguistik Kebudayaan.

Lingua, (2017), 14(1): 39 54.

Sistem sapaan kekerabatan bahasa Sasak perlu diteliti karena dalam berkomunikasi, kata sapaan merupakan kata yang sangat tinggi frekuesi pemakainya sehingga perlu dideskripsikan dengan segera. Manfaat lainya adalah bahwa hasil penelitian ini dapat memperluas khazanah kepustakaan sosiolingustik pada umumnya.

Objek penelitian ini adalah sistem dan bentuk sapaan kekerabatan yang berlaku dalam masyarakat penutur bahasa Sasak. Sistem sapaan yang dimaksudkan disini mengacu pada norma yang relatif bersifat tetap dan selalu dipakai serta dipedomani oleh masyarakat penuturnya dalam bertutur sapa anatara anggota masyarakat bahasa itu. Yang dimaksud dengan bentuk sapaan ialah kata yang dipakai menyapa orang yang diajak berbicara dalam suatu peristiwa tutur, seperti menyapa Amaq 'Bapak' dan Tuaq 'Paman' dalam konstruksi Amaq yak lalo jok bangket 'Bapak akan pergi ke sawah' atau Tuaq wah lalo jok kebon 'Paman suadah pergi ke kebun'.

Kata sapaan kekerabatan dalam bahasa Sasak beraneka bentuk, bergantung pada konteks pemakaiannya, misalnya, ada kata-kata petunjuk hubungan kekerabatan yang digunakan sebagai kata ganti. Yang dimaksud dengan hubungan kekerabatan itu adalah hubungan yang terjadi antara keluarga, yakni bubungan antara anak dan orang tua, hubungan antara suami dan istri, hubungan antara kakak dan adik, dan sebagainya.

Dalam kaitan dengan itu, permasalahannya adalah bagaimana wujud sistem sapaan kekerabatan bahasa Sasak dalam konteks sosial budaya dilihat dari variabelvariabel tertentu. Variabel yang dimaksudkan ialah bubungan antar penutur, tempat, situasi, usia, dan jenis kelamin. Hubungan antarapenutur dipilih menjadi hubungan kekerabatan, tingkat kekerabatan, dan hubungan antarlapisan sosial. Berdasarkan variabel tersebut, masalah penelitian sistem sapaan kekerabatan bahasa Sasak menyangkut pola pemakaian sapaan dilihat dari variabel (1) hubungan antarpenutur, baik hubungan kekerabatan, tingkat kekerabatan maupun hubungan antarlapisan sosial, (2) variabel situasi dan tempat (setting), (3) variabel usia, dan (4) variabel jenis kelamin.

Faktor luar bahasa seperti yang dikemukakan itulah yang menjadikan bahwa seperangkat bentuk sapaan sebagai variasi lingual. Setiap bahasa mempunyai sejumlah bentuk kebahasaan yang dipakai untuk menyapa dalam awal peristiwa tutur sapa.

Suatu dimensi penting dalam bahasa adalah bisa menggunakan bahasa untuk berbagai tujuan yang berbeda-beda. Di dalam kegiatan sehari-hari, kita mungkin menggunakan bahasa secara referensial, secara afektif, secara estetik atau untuk basabasi belaka (phatic) (Linda, 2007:12). Salam dan sapaan, walaupun kedengarannya remeh dan sepele, akan tetapi memiliki makna sosial yang sangat penting. Salam dan sapaan berfungsi sebagai tanda kita memperhatikan orang yang disapa (Kartomiharjo, 1988:27). Mengingatkan begitu pentingnya penggunaan kata sapaan dalam kehidupan sehari hari, bila kita lupa menggunakan maka kita sering dianggap sombong, lupa diri dan sebagainya.

Selanjutnya Kartomiharjo mengutip pendapat Malinowasky (1988:28) mendefenisikan salam dan sapaan sebagai ucapan yang biasanya yang terdiri dari sepatah dua patah kata yang tidak hanya menyampaikan pesan, gagasan akan tetapi sebagai tanda adanya ikatan kelas sosial. Ada dua fungsi sapaan menurut Chaika Via 
LINGUA, Vol. 14, No. 1, Maret 2017

p ISSN: 1979 9411; e -ISSN: 2442 238X

Http://lingua.pusatbahasa.or.id; Email: presslingua@gmail.com

Center of Language and Culture Studies, Surakarta, Indonesia

Haeruddin. 2017. Sistem Sapaan Kekerabatan Suku Sasak: Kajian Linguistik Kebudayaan.

Lingua, (2017), 14(1): 39 54.

Johar Aamir (1982:46) pertama sapaan digunakan sebagai kekuasaan dan solidaritas, kedua sapaan diguunakan berulang-ulang terus dalam percakapan untuk memperkuat hubungan keintiman dan kekuasaan antara penyapa dan disapa.

Sejalan dengan apa yang disampaikan Chaika di atas, Kridalaksana Via Johar (1982:55) mengatakan sistem sapaan adalah sistem yang mengikat semua unsur sistem bahasa yang menandai status dan peran partisipan dalam berkomonikasi dengan bahasa. Selanjutnya dia menyatakan ada sembilan jenis kata sapaan dalam bahasa Indonesia untuk menyapa seseorang, yaitu: (1) Kataganti orang (kamu, engkau). (2) Nama diri ( Abdul, Zilali, Nanda), (3) Istilah kekerabatan (Bapak, Ibu, Paman, Kakak) (4) Gelar dan pangkat (guru, doktor,ustad), (5) Bentuk pelaku pronomina (pendengar, penonton dan pemirsa), (6) Bentuk nomina ku (Tuhan ku, Bapakku), (7) Kata deiksis (ini, itu sini, sin) bentuk nomina lain (tuan, uwak nona), dan (9) Bentuk zero (penghilangan kata sapaan) Menurut Alwi (1988:258) keanekaragaman bahasa dan budaya daerah pemakai bahasa Indonesia, memiliki bentuk bentuk lain sebagai penyapa untuk persona kedua dan pengacu untuk persona pertama dan ketiga. Sehubungan dengan hal tersebut bahasa Sasak juga memiliki bentuk personal bentuk kedua bebas untuk menyapa, antara lain, side, plungguh, plinggih, kamu dan lain sebagainya.

Nababan (1986) mengatakan bahwa setiap bahasa mempunyai empat golongan fungsi, yakni (1) fungsi kebudayaan, (2) fungsi kemasyarakatan, (3) fungsi perorangan, dan(4) fungsi pendidikan. Keempat macam fungsi itu tentu berkaitan juga sebab perorangan adalah masyarakat yang hidup dalam masyarakat itu sesuai dengan polapola kebudayaannya yang diwariskan dan dikembangkan melalui pendidikan. Fungsi bahasa dalam kebudayaan dapat diperinci lagi ke dalam tiga fungsi, yaitu: (1) sarana perkembangan kebudayaan, (2) jalur penerus kebudayaan, dan (3) inventaris ciri-ciri kebudayaan (Sibarani, 2004:57).

Hubungan antara bahasa dan kebudayaan dimunculkan juga secara konseptualteroretis, yang tidak hanya dinamai secara bervariasi, tetapi terutama dimaknai secara berbeda. Foley (1997:1) menggunakan istilah anthropological linguistics 'linguistik antropologi' yang mengaji bahasa dari perspektif antroplologi untuk menemukan dan menentukan makna di balik pengunaannya (lihat juga Pastika, 2004:37). Konsep anthropological linguistics disamakan dengan konsep linguistic anthropology oleh Duranti (1997:1). Di samping kedua istilah tersebut, pada sebelum tahun 1940-an, di Eropa dikenal pula istilah ethnolinguistics. Dengan mengutip pendapat Cardona, Duranti (1997:2) menjelaskan bahwa istilah ethnolinguistics dalam bahasa Inggris sepadan dengan istilah étnolinguistica dalam bahasa Rusia, ethnolinguistique dalam bahasa Perancis, ethnolinguistik dalam bahasa Jerman, etnolingüística dalam bahasa Spanyol, dan etnolingiuística dalam bahasa Portugis. Uraian ini menunjukkan bahwa istilah etnolinguistik pernah sangat populer di Eropa, yang ketika itu di Amerika dikenal dengan istilah antropologi linguistik.

Dalam hubungan ini, bahasa berperan sebagai alat atau sarana kebudayaan, baik untuk perkembangan, transmisi maupun penginventarisannya. Kebudayaan Indonesia 
LINGUA, Vol. 14, No. 1, Maret 2017

p ISSN: 1979 9411; e -ISSN: 2442 238X

Http://lingua.pusatbahasa.or.id; Email: presslingua@gmail.com

Center of Language and Culture Studies, Surakarta, Indonesia

Haeruddin. 2017. Sistem Sapaan Kekerabatan Suku Sasak: Kajian Linguistik Kebudayaan.

Lingua, (2017), 14(1): 39 54.

dikembangkan melalui bahasa Indonesia. Pemerkayaan khazanah kebudayaan Indonesia melalui kebudayaan daerah dan kebudayaan asing, misalnya, dilakukan dengan menggunakan bahasa Indonesia. Khazanah kebudayaan Indonesia tersebut juga disebarkan atau dijelaskan melalui bahasa Indonesia sebab penerimaan kebudayaan hanya bias terwujud apa bila kebudayaan itu dimengerti, dipahami, dan dijunjung masyarakat pemilik kebudayaan itu sendiri. Dengan demikian bahasa memainkan peranan penting. Bahkan, sering dinyatakan bahwa kebudayaan dapat terjadi apabila bahasa ada karena bahasalah yang menginginkan terbentuknya kebudyaan (Sibarani, 2004:58).

Kebudayaan dalam arti luas bias mencakup hal-hal seperti kebiasaan, adat, hokum, nilai, lembaga sosial, religi, teknologi, bahasa. Bagi antropologi, bahasa seringkali dianggap sebagai ciri penting bagi jati diri (identitas) bagi sekelompok orang berdasarkan etnik. Masyarakat Jakarta dapat dipilah-pilah berdasarkan etnik mereka, menjadi kelompok Cina, Arab, Batak, Jawa, Sunda, Betawi dan sebagainya, dan ciri atau jati dari tiap kelompok itu adalah bahasa (Sumarsono, 2011:13).

Kata masyarakat biasanya diartikan sebagai sekelompok orang (dalam jumlah yang banyaknya relatif), yang merasa sebangsa, seketurunan, sewilayah tempat tinggal, atau yang mempunyai kepentingan sosial yang sama. Karena itu, bias disebut masyarakat Indonesia, masyarakat Betawi, masyarakat Rt 001, atau juga masyarakat Eropa. Lalu, apakah yang dimaksud dengan masyarakat bahasa? Yang dimaksud dengan masyarakat hahasa adalah sekelompok orang yang merasa menggunakan bahasa yang sama (Chaer, 2012:59). Dengan demikian kalau ada sekelompok orang yang merasa sama-sama menggunakan bahasa Sunda, maka bias dikatakan mereka adalah masyarakat bahasa Sunda; kalau ada sekelompok orang merasa menggunakan bahasa Mandailing, maka mereka bias disebut masyarakat bahasa Mandailing.

\section{METODE}

\section{Subjek Kajian}

Metode yang digunakan dalam penelitian ini adalah metode deskriptif kualitatif dengan pendekatan metode etnoinguistik. Etnolinguistik merupakan ilmu yang menelaah bahasa bukan hanya dari strukturnya, tapi lebih pada fungsi dan pemakaiannya dalam konteks situasi sosial budaya. Spradley (1997:140) berpendapat bahwa setiap bahasa mempunyai banyak istilah penduduk asli yang digunakan oleh masyarakat untuk merujuk hal-hal yang mereka alami dan nama benda yang ada di sekitar mereka. Duranti (1997:84) menjelaskan bahwa karena studi etnolinguistik mengkaji bentuk linguistik yang mengungkapkan unsur kehidupan sosial, maka peneliti dalam bidang ini harus memiliki cara untuk menghubungkan bentuk bahasa dengan kebiasaan budaya. Misalnya, orang Sasak dalam menggunakan sapaan kekerabatan. Sapaan kekerabatan suku Sasak tidak dapat dilepaskan dari adat istiadat dan budaya setempat.

Narasumber yang dijadikan sampel adalah sebagai berikut (1) Jenis kelamin lakilaki atau perempuan. (2) Orang tersebut bersedia menjadi informan dan bersedia 
LINGUA, Vol. 14, No. 1, Maret 2017

p ISSN: 1979 9411; e ISSN: 2442 238X

Http://lingua.pusatbahasa.or.id; Email: presslingua@gmail.com

Center of Language and Culture Studies, Surakarta, Indonesia

Haeruddin. 2017. Sistem Sapaan Kekerabatan Suku Sasak: Kajian Linguistik Kebudayaan.

Lingua, (2017), 14(1): 39 54

meluangkan waktunya untuk memberikan informasi yang diperlukan untuk pengumpulan data. (3) Berusia antara 20-60 tahun (tidak pikun), maksudnya dengan usia diatas 20-50 tahun dianggap dewasa dan memiliki kosakata bahasa dengan baik. (4) Dibesarkan di Ampenan. (5) pendidikan formal sekurang-kurangnya SD. (6) Sehat jasmani dan rohani, maksudnya sehat jasmani yaitu tidak cacat berbahasa dan memiliki pendengaran yang tajam untuk menangkap pertanyaan dengan tepat; sedangkan sehat rohani maksudnya tidak gila atau pikun. (7) Mobilitas keluar daerah rendah.

\section{Populasi}

Peneliti melakukan penelitian ini di Kota Mataram, yang terdiri dari enam kecamatan yaitu (1) Kecamatan Mataram (2) Kecamatan Sandubaya (3) Kecamatan Cakranegara (4) Kecamatan Selaparang (5) Kecamatan Ampenan dan (6) Kecamatan Sekarbela. Jumlah narasumber 60 orang, masing-masing kecamatan 10 orang narasumber yang mewakili masing-masing kecamatan yang ada di Kota Mataram. Pembatasan jumlah itu karena keterbatasan waktu dan tenaga. Namun jumlah itu dianggap sudah memadai untuk mendapatkan data yang diperlukan. Hasil pengamatan terhadap nilai, makna dan simbol-simbol kebudayaan, peneliti berusha mewancarai teman, tokoh masyarakat, budayawan, tokoh seni yang ada di daerah penelitian. Kesemuanya itu, penulis lakukan dengan berbagai metode penelitian, seperti metode simak yang dilanjutkan dengan teknik rekam, langsung teknik catat. Sementara itu, pengumpulan data dalam telaah masalah tersebut dengan teknik percakapan, yang meliputi teknik pancing, cakap bertemu muka, teknik sadap, simak libat cakap, dan teknik simak bebas libat cakap, terhadap objek yang diteliti dan dituju.

Sesuai dengan tujuan penelitian ini, yaitu mengkaji sistem dan bentuk sapaan kekerabatan bahasa Sasak, narasumber adalah penutur asli bahasa Sasak yang bertempat tinggal, lahir dan dibesarkan di Mataram suku Sasak. Dalam hal itu yang dimaksud dengan penduduk asli Sasak adalah orang-orang yang menggunakan bahasa ibu bahasa Sasak. Walaupun bahasa Sasak mengenal beberapa dialek, narasumber penelitian ini tidak berasal dari salah satu penutur dialek Sasak. Hal itu dengan pertimbangan bahwa penutur basasa Sasak memiliki sifat homogeny. Jadi, penutur bahasa Sasak yang dijadikan narasumber adalah penutur yang dapat memberikan informasi tentang bentuk sapaan yang umum berlaku dalam sistem bertutur sapa.

\section{HASIL DAN BAHASAN}

\section{Sistem Sapaan Umum}

Bentuk Sapaan Kekerabatan Suku Sasak setiap daerah memiliki sapaan kekerabatan yang khas. Sistem sapaan kekerabatan suku Sasak tentu berbeda dengan sistem sapaan masyarakat Jawa, Bali, Kalimantan, Sumatra, Sumbawa, Bima dan daerah-daerah lain di Indonesia. Sapaan yang digunakan oleh masyarakat menunjukkan identitas lokal masyarakat tersebut. Misalnya, untuk sebutan Saudara, orang Jawa menggunakan sedulur atau sederek, sedangkan. Demikian juga masyarakat 
LINGUA, Vol. 14, No. 1, Maret 2017

p ISSN: 1979 9411; e -ISSN: 2442 238X

Http://lingua.pusatbahasa.or.id; Email: presslingua@gmail.com

Center of Language and Culture Studies, Surakarta, Indonesia

Haeruddin. 2017. Sistem Sapaan Kekerabatan Suku Sasak: Kajian Linguistik Kebudayaan.

Lingua, (2017), 14(1): 39 54.

Sumbawa, Sumatra, Bali, dan seterusnya. Mereka memiliki sapaan yang khas menggambarkan dari mana mereka berasal.

Sistem sapaan dalam suku Sasak berbeda halnya dengan sistem sapaan pada masyarakat suku lainnya yang ada di Indonesia. Karena perlu diketahui di suku Sasak secara umum terdapat tiga macam lapisan sosial masyarakat. Masing-masing lapisan sosial masyarakat di kenal dengan kasta yang mempunyai kriteria tersendiri (1) Golongan Ningrat, golongan ini dapat diketahui dari sapaan kebangsawanannya. Sapaan keningratan ini merupakan nama depan dari seseorang dari golongan ini. Nama depan keningratan ini adalah "lalu" untuk orang-orang ningrat pria yang belum menikah. Sedangkan apabila merka telah menikah maka nama keningratannya adalah "mamiq“. Untuk wanita ningrat nama depannya adalah " lale", bagi mereka yang belum menikah, sedangkan yang telah menikah disebut "mamiq lale". (2) Golongan Pruangse. kriteria khusus yang dimiliki oleh golongan ini adalah sebutan " bapE, "untuk kaum pria pruangse yang telah menikah. Sedangkan untuk kaum pruangse yang belum menikah tak memiliki sebutan lain kecuali nama kecil mereka. Misalnya seorang dari golongan ini lahir dengan nama si "A" maka ayah dari golongan pruangse ini disebut/dipanggil "BapE $A$ ", sedangkan ibunya dipanggil "Inaq $A$ “. Di sinilah perbedaan golongan ningrat dan pruangse. (3) Golongan Bulu Ketujur, Golongan ini adalah masyarakat biasa yang konon dahulu adalah hulubalang sang raja yang pernah berkuasa di Lombok. Kriteria khusus golongan ini adalah sebutan "amaq" bagi kaum pria yang telah menikah, sedangkan wanita adalah "inaq".

Secara linguistik, bentuk sapaan itu dikelompokkan menjadi empat macam, yaitu: (1) Sistem sapaan istilah kekerabatan. (2) Sistem sapaan kata ganti orang kedua. (3) Sistem sapaan dengan menyebut nama. (4) Sistem sapaan gelar kehormatan atau kebangsawanan.

\section{a. Sistem Sapaan Istilah Kekerabatan Inaq}

Kata sapaan inaq tergolong istilah kekerabatan, muncul dalam delapan versi, yaitu: (a) inaq 'ibu'; (b) inaq kake 'ibu yang lebih tua' (c) inaq rari/saiq (d) inaq + nama anak pertama; (e) inaq tuan 'ibu hajjah (f) inaq + nama dan (g) inaq-inaq 'ibuibu'. Versi itu dipengaruhi pola hubungan penyebab dengan pesapa atau yang disapa serta variabel lainnya. Periksa Tabel 1.

Bentuk sapaan inaq digunakan oleh penyapa pria muda dan wanita muda untuk menyapa wanita tua yang sudah mempunyai anak. Sapaan ini digunakan situasi tidak resmi dan dalam hubungan akrab. Bentuk sapaan ianq kake, digunakan oleh penyapa peria tua dan muda wanita tua dan muda unduk menyapa wanita tua baik yang sudah mempunyai anak maupun masih bujang. Sapaan ini digunakan pada situasi tidak resmi dan dalam hubungan akrab. Bentuk sapaan inaq rari, digunakan oleh penyapa peria muda dan wanita muda unduk menyapa wanita tua baik yang sudah mempunyai anak maupun masih bujang. Sapaan ini digunakan pada situasi tidak resmi dan dalam hubungan akrab. 
LINGUA, Vol. 14, No. 1, Maret 2017

p ISSN: 1979 9411; e ISSN: 2442 238X

Http://lingua.pusatbahasa.or.id; Email:presslingua@gmail.com

Center of Language and Culture Studies, Surakarta, Indonesia

Haeruddin. 2017. Sistem Sapaan Kekerabatan Suku Sasak: Kajian Linguistik Kebudayaan.

Lingua, (2017), 14(1): 39 54.

Tabel 1. Sistem Sapaan Istilah Kekerabatan Inaq

\begin{tabular}{|c|c|c|l|}
\hline No. & $\begin{array}{c}\text { Bentu k } \\
\text { Sapaan }\end{array}$ & Arti & \multicolumn{1}{|c|}{ Keterangan } \\
\hline 1 & Inaq & Ibu & Panggilan untuk orang tua wanita \\
\hline 2 & Inaq Kaka & 'Ibu de' Jawa & Kakak dari ibu atau Bapak \\
\hline 3 & inaq rari/saiq' & Bibi & Panggilan untuk bibi \\
\hline 4 & $\begin{array}{c}\text { inaq + nama } \\
\text { anak pertama }\end{array}$ & $\begin{array}{c}\text { Ibu + nama anak } \\
\text { pertama }\end{array}$ & Ibu Ali/nama anak pertam Ali \\
\hline 5 & Inaq tuan & Ibu hajjah & $\begin{array}{l}\text { Panggilan bagi ibu yang pernah naik } \\
\text { haji }\end{array}$ \\
\hline 6 & inaq + nama & Ibu + nama gadis & Ibu Siti/siti nama gadis \\
\hline 7 & Inaq-inaq & Ibu-ibu & Sapaan lebih dari dua \\
\hline
\end{tabular}

Sapaan inaq + nama anak pertama digunakan oleh penyapa peria tua dan wanita tua untuk menyapa wanita (tua, sebaya, dan muda) yang sudah mempunayi anak. Sapaan ini digunakan pada situasi tidak resmi dan dalam hubungan akrab. Selain itu, sapaan inaq tuan digunakan oleh penyapa peria (tua dan muda) dan wanita (tua dan muda) kepada yang disapa wanita (tua dan sebaya), baik yang sudah mempunyai anak maupun masih bujang, tetapi mereka sudah berhaji. Sapaan ini digunakan pada situasi tidak resmi dalam hubungan akrab. Bentuk sapaan inaq + nama digunakan oleh penyapa pria (tua dan muda) dan wanita (tua dan muda) untuk menyapa wanita (tua, sebaya, dan muda), baik yang sudah mempunyai anak maupun masih bujang. Sapaan ini digunakan pada situasi resmi dan tidak resmi dalam hubungan akrab dan tidak akrab.Bentuk sapaan inaq-inaq digunakan oleh penyapa pria (tua dan muda) dan wanita (tua dan muda) untuk menyapa lebih dari satu orang wanita (tua, sebaya dan muda), baik yang sudah mempunyai anak maupun masih bujang. Sapaan ini digunakan pada situasi resmi dan tidak resmi di dalam hubungan akrab dan tidak akrab.

\section{b. Sistem Sapaan Istilah Kekerabatan Amaq}

Kata sapaan amaq muncul dalam tiga versi. tiga versi yang dimaksud adalah sebagai berikut: (a) amaq (b) amaq + nama anak pertama dan (c) amaq kakE. Kemunculan bentuk versi itu bergantung pada pola hubungan penyebab dengan pesapa serta variabel lainnya. Jenis sapaan Imaq disajikan pada Tabel 2.

Tabel 2. Sapaan Kekerabatan Amaq.

\begin{tabular}{|c|c|c|c|}
\hline No. & Bentuk Sapaan & Arti & Keterangan \\
\hline 1 & Amaq & Bapak & Sebutan orang tua laki \\
\hline 2 & $\begin{array}{c}a m a q+\text { nama } \\
\text { anak pertama }\end{array}$ & $\begin{array}{c}\text { Bapak+nama anak } \\
\text { pertama }\end{array}$ & Amaq \\
\hline 3 & amaq kakE & Bibi & $\begin{array}{c}\text { Panggilan untuk adik wanita } \\
\text { dari saudara ibu atau bapak }\end{array}$ \\
\hline
\end{tabular}


LINGUA, Vol. 14, No. 1, Maret 2017

p ISSN: 1979 9411; e -ISSN: 2442 238X

Http://lingua.pusatbahasa.or.id; Email: presslingua@gmail.com

Center of Language and Culture Studies, Surakarta, Indonesia

Haeruddin. 2017. Sistem Sapaan Kekerabatan Suku Sasak: Kajian Linguistik Kebudayaan.

Lingua, (2017), 14(1): 39 54.

Bentuk sapaan amaq digunakan oleh penyapa peria (tua dan muda) dan wanita (tua dan muda) untuk menyapa prian tua yang sudah mempunyai anak. Bentuk sapaan ini dipakai pada situasi tidak resmi dan dalam hubungan akrab. Bentuk sapaan amaq + nama anak pertama digunakan oleh penyapa pria (tua dan muda) dan wanita (tua dan muda) untuk menyapa pria (tua, sebaya dan muda) yang sudah mempunyai anak. Bentuk sapaan ini dipakai pada situasi resmi dan tidak resmi dan dalam hubungan akrab. Bentuk sapaan amaq kake digunakan oleh penyapa peria tua dan muda wanita tua dan muda unduk menyapa pria tua baik yang sudah mempunyai anak maupun masih bujang.

\section{c. Sistem Sapaan Istilah Kekerabatan Ariq}

Tabel 3 berikut menunjukkan istilah kekerabatan Ariq. Sapaan ariq 'adik' muncul dalam dua versi. Kedua versi yang dimaksud adalah sebagai berikut: (a) ariq 'adik' (b) ariq + nama. Kemunculan bentuk versi itu bergantung pada pola hubungan antara penyapa dengan pesapa atau yang disapa serta variabel lainnya. Bentuk sapaan ariq digunakan oleh penyapa pria (tua dan muda) dan wanita (tua dan muda) untuk menyapa pria muda dan wanita muda (baik yang sudah mempunyai anak maupun masih bujang). Sapaan ini digunakan pada situasi tidak resmi dan dalam hubungan akrab. Sementara bentuk sapaan ariq + nama digunakan oleh penyapa pria tua dan wanita tua, untuk menyapa pria muda, wanita muda, baik yang sudah mempunyai anak maupun yang masih bujang. Sapaan ini dipakai pada situasi resmi dan dalam hubungan akrab dan tidak akrab.

Tabel 3. Istilah Kekerabatan Ariq.

\begin{tabular}{|c|c|c|c|}
\hline No. & $\begin{array}{c}\text { Bentuk } \\
\text { Sapaan }\end{array}$ & Arti & Keterangan \\
\hline 1 & Ariq & adik & Sebutan untuk saudara pria dan saudara wanita \\
\hline
\end{tabular}

\section{d. Sistem Sapaan Istilah Kekerabatan AnakE}

Sistem sapaan istilah kekerabatan anakE 'nak' muncul dengan dua variasi. dua varasi yang dimaksudkan adalah sapaan anakE dan anakE + nama. Kemunculan kedua bentuk tersebut tergantung pada pola hubungan penyebab dengan pesapa serta faktor variabel-variabel lain. Bentuk sapaan anakE digunakan oleh penyapa pria tua dan wanita tua untuk menyapa pria muda dan wanita muda yang masih bujangan. Sapaan ini digunakan dalam situasi resmi dan tidak resmidan dalam hubungan akrab dan tidak akrab. Selanjutnya sapaan dalam bentuk anakE + nama digunakan oleh penyapa pria tua dan wanita tua untuk menyapa pria dan wanita muda (bujang). Sapaan ini digunakan pada situasi resmi dan tidak resmi dan dalam hubungan akrab dan tidak akrab. Periksa Tabel 4. 
LINGUA, Vol. 14, No. 1, Maret 2017

p ISSN: 1979 9411; e ISSN: 2442 238X

Http://lingua.pusatbahasa.or.id; Email: presslingua@gmail.com

Center of Language and Culture Studies, Surakarta, Indonesia

Haeruddin. 2017. Sistem Sapaan Kekerabatan Suku Sasak: Kajian Linguistik Kebudayaan.

Lingua, (2017), 14(1): 39 54.

Tabel 4. Istilah kekerabatan AnakE

\begin{tabular}{|c|c|c|l|}
\hline No. & Bentuk Sapaan & Arti & \multicolumn{1}{c|}{ Keterangan } \\
\hline 1 & AnakE & Anak & Sebutan untuk anak pria dan wanita \\
\hline 2 & anakE + nama & $\begin{array}{c}\text { anak+nama } \\
\text { anak }\end{array}$ & $\begin{array}{l}\text { Panggilan untuk anak dengan } \\
\text { menyebut nama }\end{array}$ \\
\hline
\end{tabular}

\section{e. Sistem Sapaan Istilah Kekerabatan Kakaq}

Bentuk sistem sapaan kekerabatan kakaq 'kakak' muncul dengan lima vareasi. lima varasi yang dimaksudkan adalah sebagai berikut: (a) kakaq 'kakak'; (b) kak tuan 'kak haji'; (c) kak + nama panggilan. Kemunculan bentuk variasi ini bergantung pada pola hubungan antara penyapa dengan yang disapa (pesapa) serta variabel lainya. Periksa Tabel 5.

Tabel 5. Istilah kekerabatan Kakaq

\begin{tabular}{|c|c|c|l|}
\hline No. & $\begin{array}{c}\text { Bentuk } \\
\text { Sapaan }\end{array}$ & Arti & \multicolumn{1}{|c|}{ Keterangan } \\
\hline 1 & kakaq & kakak & $\begin{array}{l}\text { Sebutan untuk saudara yang lebih } \\
\text { tua baik pria maupun wanita }\end{array}$ \\
\hline 2 & Kak tuan & $\begin{array}{c}\text { Kakak yang pernah } \\
\text { naik haji }\end{array}$ & $\begin{array}{l}\text { Sapaan kepada saudara pria atau } \\
\text { wanita yang sudah naik haji }\end{array}$ \\
\hline 3 & $\begin{array}{c}\text { Kak+nama } \\
\text { panggilan }\end{array}$ & $\begin{array}{c}\text { Kakak + nama } \\
\text { panggilan }\end{array}$ & $\begin{array}{l}\text { Sapaan kepada saudara pria dan } \\
\text { wanita }\end{array}$ \\
\hline
\end{tabular}

Bentuk sapaan dengan variasi kakaq digunakan oleh penyapa pria (tua dan muda) dan wanita (tua dan muda) untuk menyapa pria tua dan wanita tua, baik yang sudah kawin maupun bujangan. Sapaan ini dipakai terutama pada situasi tidak resmi dan dalam hubungan akrab. Bentuk sapaan kak tuan digunakan oleh penyapa pria (tua dan muda) dan wanita (tua dan muda) untuk menyapa pria tua dan wanita tua (yang sudah naik haji), baik bagi mereka yang sudah mempunyai anak maupun masih bujang. Sapaan ini dipakai pada situasi resmi dan tidak resmi dalam hubungan akrab dan tidak akrab. Kak + nama panggilan digunakan oleh penyapa pria (tua dan muda) dan wanita (tua dan muda) untuk menyapa pria tua dan wanita tua (bujang). Sapaan ini dipakai pada situasi resmi dan dalam hubungan akrab.

\section{f. Sistem Sapaan Istilah Kekerabatan Papuk MamE /Papuk NinE}

Bentuk sapaan istilah kekerabatan papuk muncul dalam tiga variasi. Ketiga variasi yang dimaksud adalah sebagai berikut: (a) papuk mamE 'kakek'; (b) papuk nine 'nenek'; (c) papuk + nama. Kemunculan bentuk variasi tersebut ditentukan oleh beberapa faktor. Faktor penentu yang dimaksud adalah (a) partisipan, (b) situasi, dan (c) latar. Periksa Tabel 6. 
LINGUA, Vol. 14, No. 1, Maret 2017

p ISSN: 1979 9411; e ISSN: 2442 238X

Http://lingua.pusatbahasa.or.id; Email: presslingua@gmail.com

Center of Language and Culture Studies, Surakarta, Indonesia

Haeruddin. 2017. Sistem Sapaan Kekerabatan Suku Sasak: Kajian Linguistik Kebudayaan.

Lingua, (2017), 14(1): 39 54.

Tabel 6. Kekerabatan Papuk MamE

\begin{tabular}{|c|c|c|l|}
\hline No. & $\begin{array}{c}\text { Bentuk } \\
\text { Sapaan }\end{array}$ & Arti & \multicolumn{1}{|c|}{ Keterangan } \\
\hline 1 & Papuk MamE & Kakek & Sebutan untuk kakek \\
\hline 2 & Papuk ninE & Nenek & Panggilan untuk nenek \\
\hline 3 & $\begin{array}{c}\text { Papuk }+ \\
\text { nama }\end{array}$ & $\begin{array}{c}\text { Kakek atau nenek }+ \\
\text { nama }\end{array}$ & $\begin{array}{l}\text { Panggilan untuk kakek atau nenek } \\
\text { ditambah nama }\end{array}$ \\
\hline
\end{tabular}

Bentuk sapaan papuk mamE dan papuk ninE digunakan oleh penyapa pria dan wanita (tua dan muda) untuk menyapa pria dan wanita tua. Sapaan ini digunakan pada situasi resmi dan tidak resmi dan dalam hubungan akrab. Bebtuk sapaan papuk + nama digunakan oleh penyapa pria muda dan wanita muda untuk menyapa pria tua dan wanita muda untuk menyapa pria tua dan wanita tua, aik yang sudah mempunyai anak maupun yang masih bujang. Sapaan ini dipakai pada situasi resmi dan tidak resmi dan dalam hubungan akrab.

\section{g. Sistem Sapaan Istilah Kekerabatan Duan 'keponakan'}

Bentuk sapaan istilah duan, tidak memiliki variasi. Kemunculannya sangat dipengaruhi oleh beberapa faktor. Faktor yang dimaksud adalah (a) partisipan (b) situasi (c) latar. Bentuk sapaan duan digunakan oleh penyapa pria tua dan wanita tua, untuk menyapa pria muda bujang dan wanita muda bujang. Sapaan ini dipakai pada situasi resmi dan tidak resmi dalam hubungan akrab dan tidak akrab. Periksa tabel 7.

Tabel 7. Istilah Kekerabatan Duan 'keponakan'

\begin{tabular}{|c|c|c|c|}
\hline No. & $\begin{array}{c}\text { Bentuk } \\
\text { Sapaan }\end{array}$ & Arti & Keterangan \\
\hline 1 & Duan & Keponakan & Sebutan untuk keponakan \\
\hline
\end{tabular}

\section{h. Sistem Sapaan Istilah Kekerabatan Dedare 'gadis'}

Bentuk sapaan istilah kekerabatan dedare tidak memiliki variasi bentuk. Kemunculan bentuk sapaan ini dipengaruhi oleh hubungan antar penyapa dengan pesapa secara variabel lainnya, seperti situasi dan latar. Sapaan dedare digunakan oleh penyapa pria tua dan wanita tua, untuk menyapa wanita muda (gadis) yang masih bujang. Sapaan ini dipakai pada situasi tidak resmi dan dalam hubungan akrab. Periksa Tabel 8.

Tabel 8. Istilah kekerabatan Dedare gadis

\begin{tabular}{|c|c|c|c|}
\hline No. & Bentuk Sapaan & Arti & Keterangan \\
\hline 1 & $D E d a r E$ & gadis & Sebutan untuk gadis \\
\hline
\end{tabular}


LINGUA, Vol. 14, No. 1, Maret 2017

p ISSN: 1979 9411; e ISSN: 2442 238X

Http://lingua.pusatbahasa.or.id; Email:presslingua@gmail.com

Center of Language and Culture Studies, Surakarta, Indonesia

Haeruddin. 2017. Sistem Sapaan Kekerabatan Suku Sasak: Kajian Linguistik Kebudayaan.

Lingua, (2017), 14(1): 39 54

\section{i. Sistem Sapaan Istilah Kekerabatan Tuaq 'paman'}

Bentuk sapaan isilah kekerabatan tuaq muncul dalam dua variasi. Kedua variasi itu adalah (a) tuaq, (b) tuaq + nama, kemuculan kedua variasi itu ditentukan oleh pola hubungan sapa antara penyapa, pesapa serta variabel lainnya, seperti situasi dan latar. Bentuk sapaan tuaq digunakan oleh penyapa pria muda dan wanita muda untuk menyapa pria (tua dan sebaya) dan wanita (tua dan sebaya), baik yang sudah mempunyai anak maupun yang masih bujang. Bentuk sapaan tuaq + nama digunakan oleh penyapa pria muda dan wanita muda untuk menyapa pria tua yang sebaya. Sapaan ini dipakai pada situasi resmi dan tidak resmi dalam hubungan akrab dan tidak akrab. Periksa Tabel 9.

Tabel 9. Istilah kekerabatan Tuaq paman

\begin{tabular}{|c|c|c|c|}
\hline No. & Bentuk Sapaan & Arti & Keterangan \\
\hline 1 & Tuaq & Paman & Sebutan untuk paman \\
\hline 2 & Tuaq+nama & Paman+nama & $\begin{array}{c}\text { Panggilan untuk paman dengan } \\
\text { penambahan nama }\end{array}$ \\
\hline
\end{tabular}

\section{Sistem Sapaan Kata Ganti Orang Kedua}

Selain istilah sapaan kekerabatan bahasa Sasak juga menggunakan kata ganti orang kedua (KGO II) sebagai sapaan. Adapun bentuk-bentuk sapaan KGO II dalam bahasa Sasak, yang ditemukan yaitu (a) kamu (b) side (c) plungguh/plinggih

\section{a. Sistem Sapaan Kata Ganti Orang II kamu 'E ngkau”}

Bentuk sapaan KGO II kamu muncul tanpa variasi. Munculnya sapaan ini dipengaruhi oleh pola hubungan antara penyapa dengan pesapa. Di samping itu, variabel seperti situasi dan latar juga ikut memegaruhi pemakaian bentuk sapaan KGO II itu. Bentuk sapaan itu digunakan oleh penyapa pria (tua dan muda) dan wanita (tua dan muda), untuk menyapa pria (sebaya, dan muda) dan wanita (sebaya dan muda) baik yang sudah menikah maupun yang belum menikah. Sapaan ini dipakai pada situasi resmi dan tidak resmi dalam hubungan akrab dan didak akrab. Sapaan kamu termasuk sapaan yang kasar bagi yang disap dalam bahsa Sasak.

\section{b. Sistem Sapaan Kata Ganti Orang II SidE 'Kamu”}

Bentuk sapaan KGO II sidE tidak memiliki variasi. Munculnya bentuk sapaan KGO II ini bergantung pada pola hubungan antara penyapa dengan pesapa. Disamping itu, variabel-variabel lainnya seperti situasi dan latar juga ikut menentukan munculnya sapaan bentuk sidE ini. Bentuk sapaan KGO II sidE digunkan oleh penyapa pria (tua dan muda) dan wanita (tua dan muda), untuk menyapa pria dan wanita (tua atau yang lebih umurnya dari penyapa) baik yang sudah kawin maupun belum. Sapaan ini dipakai pada situasi resmi dan tidak resmi dalam hubungan akrab dan tidak akrab. 
LINGUA, Vol. 14, No. 1, Maret 2017

p ISSN: 1979 9411; e ISSN: 2442 238X

Http://lingua.pusatbahasa.or.id; Email: presslingua@gmail.com

Center of Language and Culture Studies, Surakarta, Indonesia

Haeruddin. 2017. Sistem Sapaan Kekerabatan Suku Sasak: Kajian Linguistik Kebudayaan.

Lingua, (2017), 14(1): 39 54

\section{c. Sistem Sapaan Kata Ganti Orang II PElungguh 'Anda"}

Bentuk sapaan KGO II PElungguh 'Anda' tidak memiliki variasi. Munculnya bentuk sapaan KGO II PElungguh ini ditentukan oleh faktor hubungan antaran penyapa dengan pesapa. Disamping itu, variabel-variabel lainnya seperti situasi dan latar juga ikut mempengaruhi munculnya sapaan bentuk ini. Bentuk sapaan KGO II PElungguh digunkan oleh penyapa pria (tua dan muda) dan wanita (tua dan muda), untuk menyapa pria dan wanita (tua yang dihormati) baik yang sudah kawin maupun belum. Sapaan ini dipakai pada situasi resmi dan tidak resmi dalam hubungan akrab dan tidak akrab.

\section{Sistem Sapaan dengan Menyebut Nama}

Sistem sapaan dengan menyebut nama dapat dikelompokkan menjadi lima jenis, yaitu: (a) sistem sapaan dengan menyebut nama sendiri; (b) sistem sapaan dengan menyebut nama anak I; (c) sistem sapaan dengan menyebut nama panggilan; (d) sistem sapaan dengan menyebut nama ejekan; (e) sistem sapaan dengan menyebut nama suami.

\section{a. Sistem Sapaan dengan Menyebut Nama Diri}

Kemunculan sistem sapaan dengan menyebut nama diri sangat dipengaruhi oleh pola hubungan antara penyapa dengan pesapa. Disamping itu, variabel lainnya seperti situasi dan latar juga ikut menentukan munculnya sapaan itu. Bentuk sapaan dengan menyebut nama diri digunakan oleh penyapa pria tua dan muda serta wanita tua dan muda untuk menyapa pria (tua, sebaya dan muda), dan wanita (tua, sebaya dan muda) baik yang sudah kawin maupun yang masih bujang. Bentuk sapaan ini bipakai pada situasi resmi dan tidak resmi hubungan akrab dan tidak akrab.

\section{b. Sistem Sapaan dengan Menyebut Nama Anak Pertama}

Kemunculan sistem sapaan dengan menyebut nama anak pertama kemunculannya dipengaruhi oleh pola hubungan antara penyapa dengan yang disapa. Disamping itu, variabel lainnya seperti situasi dan latar juga ikut menentukan kemunculan bentuk sapaan dengan menyebut nama anak pertama ini. Pemakaian sapaan dengan menyebut anak pertama. Bentuk sapaan dengan menyebut anak pertama digunakan oleh penyapa pria tua dan wanita tua untuk menyapa pria (tua, sebaya, dan muda), dan wanita (tua, sebaya, dan muda), yang sudah mempunyai anak. Bentuk sapaan ini dipakai pada situasi tidak resmi dan dalam hubungan akrab.

\section{c. Sistem Sapaan dengan Menyebut Nama Panggilan}

Kemunculan sistem sapaan dengan menyebut nama panggilan dipengaruhi oleh pola hubungan antara penyapa dengan pesapa. Disamping itu, variabel lain juga ikut memengaruhi munculnya bentuk sapaan nama panggilan itu. Untuk mengetahui tentang pemakaian sapaan ini. Bentuk sapaan panggilan itu digunakan oleh penyapa pria (tua dan muda) dan wanita (tua dan muda) untuk menyapa pria (tua, sebaya dan muda), dan wanita (tua, sebaya dan muda), baik yang sudah kawin maupun yang masih bujang. 
LINGUA, Vol. 14, No. 1, Maret 2017

p ISSN: 1979 9411; e ISSN: 2442 238X

Http://lingua.pusatbahasa.or.id; Email: presslingua@gmail.com

Center of Language and Culture Studies, Surakarta, Indonesia

Haeruddin. 2017. Sistem Sapaan Kekerabatan Suku Sasak: Kajian Linguistik Kebudayaan.

Lingua, (2017), 14(1): 39 54

Bentuk sapaan nama panggilan dipakai dalam situasi tidak resmi dalam hubungan akrab.

\section{d. Sistem Sapaan dengan Menyebut Nama Ejekan}

Kemunculan sapaan dengan menyebut nama ejekan dipengaruhi oleh pola hubungan sapa antar penyapa dengan pesapa. Disamping itu, variabel lainnya seperti situasi dan latar juga ikut memengaruhi munculnya bentuk sapaan ini. Bentuk sapaan nama ejekan digunakan oleh penyapa pria (tua dan muda) dan wanita (tua dan muda) untuk menyapa pria (tua, sebaya dan muda) dan wanita (tua, sebaya dan muda), baik yang sudah kawin maupun yang belum. Bentuk sapaan itu umumnya digunakan dalam situasi tidak resmi dan hubungan akrab.

\section{e. Sistem Sapaan dengan Menyebut Nama Suami}

Kemunculan sistem sapaan dengan menyebut nama suami dipengaruhi oleh hubungan antara penyapa dengan pesapa atau yang disapa. Disamping itu variabel seperti situasi dan latar (tempat) juga ikut menentukan munculnya sapaan itu. Bentuk sapaan nama suami digunakan oleh penyapa pria maupun wbanita tua untuk menyapa wanita (tua dan sebaya) yang sudah kawin. Bentuk sapaan dengan menyebut nama suami umumnya digunakan, baik dalam situasi resmi maupun tidak resmi dan dalam hubungan akrab.

\section{SIMPULAN}

Bahasa Lombok merupakan bagian kebudayaan dan wahana kebudayaan suku Sasak yang memiliki fungsi sosial bagi kehidupan kemasyarakatan para penuturnya dan pendukungnya. Hal ini menunjukkan bahwa bahasa Sasak mempunyai hubungan yang sangat erat dengan struktur dan sistem sosial masyarakat penuturnya. Keeratan hubungan itu memperlihatkan keteraturan pemakaian bahasanya dalam jaringan komunikasi verbal. Salah satu wujud keteraturan bahasa Sasak dalam konteks sosial suku Sasak adalah adanya sistem dan bentuk sapaan bahasa Sasak.

Sistem sapaan bahasa Sasak yang dimaksud itu secara linguistik budaya dibangun oleh seperangkat bentuk kebahasaan yang digolongkan sebagai kata sapaan. Penggolongan kata sapaan itu dapat dirinci sebagai berikut. (1) Istilah kekerabatan baik untuk pria maupun untuk wanita, antara lain: inaq 'ibu', amaq 'bapak', papuq 'nenek/kakek', tuaq 'paman', ariq 'adik'. (2) Kata ganti orang kedua (KGO II) terdiri atas kata ganti orang kedua tunggal seperti kamu artinya engkau, sidE 'kamu', pElungguh 'kamu untuk bangsawan. (3) Penyebutan nama dari pihak pesapa antara lain dengan menyebut nama, menyebut anak pertama, nama cucu pertama, nama panggilan, nama ejekan dan nama suami. Penyebutan diri dari pihak penyapa, sudah umum digunakan bentuk tiang 'saya', kaji 'hamba' dan menyebut nama penyapa sendiri.

Berdasarkan kajian itu, ternyata bahwa bentuk sapaan yang muncul sesuai dengan variabel yang telah disebutkan diatas, bervariasi pula secara geografis, yaitu sesuai dengan lokasi dialek-dialek bahasa Sasak. Akan tetapi, dalam penelitian ini tidak 
LINGUA, Vol. 14, No. 1, Maret 2017

p ISSN: 1979 9411; e ISSN: 2442 238X

Http://lingua.pusatbahasa.or.id; Email: presslingua@gmail.com

Center of Language and Culture Studies, Surakarta, Indonesia

Haeruddin. 2017. Sistem Sapaan Kekerabatan Suku Sasak: Kajian Linguistik Kebudayaan.

Lingua, (2017), 14(1): 39 54.

dibicarakan bentuk sapaan yang berasal dari dialek-dialek tertentu dalam bahasa Sasak. Bentuk sapaan yang dikaji adalah menyangkut sapaan bahasa Sasak yang sudah umum digunakan oleh penuturnya sehari-hari. Jadi, kajian sapaan ini didasarkan atas pertimbangan bahwa bahasa Sasak atau penutur bahasa Sasak bersifat homogeny.

\section{DAFTAR PUSTAKA}

Chaer, Abdul. 2012. Linguistik Umum. Jakarta: Rineka Cipta.

Duranti, A. 1997. Linguistic Anthropology. Cambridge: Cambridge University Press.

Fishman, J. A. (1972). Sociolinguistics a Brief Introduction (3thEd). Massachusetts:

Newbury House Publisher.

Foley, W. A. 1997. Anthropological Linguistics: An Introduction.Oxford: Blackwell Publishers.

http://www. Dunia Pendidikan Cerdas Masyarakat dan Kebudayaan Suku Sasak di Pulau Lombok. diunduh, 14 November 2016

Harimurti Kridalaksana. 1982. Dinamika Tutur Sapa dalam Bahasa Indonesia.Jakarta:

Bahatara.

Johar, Amir. 2011. Jurnal Linguistik Indonesia. Jakarta: Atma Jaya.

Purwa, I Made dkk. 2003 Sistem Sapaan Bahasa Sumbawa. Jakarta: Pusat Bahasa.

Sibarani, Robert. 2004. Antropolingustik. Medan: Poda.

Spradley, James P. 1997. Terjemahan Elizabeth, Misbah Zulfa. Metode Etnografi. Yogyakarta: Tiara Wacana.

Sumarsono. 2011. Sosiolinguistik. Yogyakarta: Pustaka Pelajar. 
LINGUA, Vol. 14, No. 1, Maret 2017

p ISSN: 1979 9411; e-ISSN: 2442 238X

Http://lingua.pusatbahasa.or.id; Email: presslingua@gmail.com

Center of Language and Culture Studies, Surakarta, Indonesia

Haeruddin. 2017. Sistem Sapaan Kekerabatan Suku Sasak: Kajian Linguistik Kebudayaan.

Lingua, (2017), 14(1): 39 54. 